\title{
Ensemble Effects of Explicit Solvation on Allylic Oxidation
}

\author{
Hung M. Le, ${ }^{*, \dagger}$ Mariano Guagliardo, ${ }^{\ddagger}$ Anne E. V. Gorden, ${ }^{\ddagger}$ and Aurora E. \\ Clark ${ }^{*, \dagger}, \boldsymbol{9}$ \\ $\dagger$ Department of Chemistry, Washington State University, Pullman, Washington 99164, \\ United States \\ $\ddagger$ Department of Chemistry and Biochemistry, Texas Tech University, Lubbock, Texas \\ 79430, United States \\ IPacific Northwest National Laboratory, Richland, Washington 99352, United States \\ E-mail: hung.le2@wsu.edu; auclark@wsu.edu
}

\begin{abstract}
Umbrella-sampling density functional theory molecular dynamics (DFT-MD) has been employed to study the full catalytic cycle of the allylic oxidation of cyclohexene using a $\mathrm{Cu}(\mathrm{II})$ (E)-6-amino-7-((2-hydroxybenzylidene)amino)quinoxalin-2-ol complex in acetonitrile, which creates the desired cyclohexenone and $\mathrm{H}_{2} \mathrm{O}$ as products. In comparison to prior study using gas-phase DFT, a significant solvent effect is observed on the rate determining allylic $\mathrm{H}$-atom abstraction step (which has a free energy barrier of $12.1 \pm 0.2 \mathrm{kcal} / \mathrm{mol})$. During the cycle, the explicit solvation and ensemble sampling of solvent configurations reveals an important dehydrogenation and re-hydrogenation step of the $-\mathrm{NH}_{2}$ ligand that is essential to catalyst recovery. This work illustrates the importance of ensemble solvent configurational sampling to reveal the breadth of processes that underpin the full catalytic cycle.
\end{abstract}




\section{Introduction}

The oxidation of an allylic $\mathrm{CH}_{2}$ group to a carbonyl is an important process in multi-step organic syntheses. ${ }^{1,2}$ Consider that $\alpha, \beta$-unsaturated enones or 1,4-enediones have been utilized as essential building components in the synthesis of numerous natural compounds and drug precursors. ${ }^{3-7}$ In general, allylic oxidation can be efficiently activated using tertbutyl hydroperoxide (TBHP) with the addition of metal catalysts. ${ }^{8-13} \mathrm{Cu}(\mathrm{II})$ complexes have been of particular interest as copper is a relatively economical and environmentally benign. For example, Yao et al. synthesized a stable aryl- $\mathrm{Cu}(\mathrm{III})$ complex that was employed for $\mathrm{C}-\mathrm{H}$ activation resulting in very good yields under aerobic conditions. ${ }^{14}$ Wang and coworkers have synthesized a $\mathrm{Cu}(\mathrm{II})$ complex for dehydrogenative aminooxygenations, wherein the $\mathrm{Cu}$ oxidation state was demonstrated to convert from $(\mathrm{Cu}(\mathrm{II})$ to $\mathrm{Cu}(\mathrm{III})) .{ }^{15} \mathrm{By}$ allowing a $\mathrm{Cu}(\mathrm{II})$-superoxide complex to react with acyl chloride substrates, Pirovano and co-workers have found the resultant complex to be a reactive nucleophile, which could be subsequently be employed for the Baeyer-Villiger oxidations of aldehydes. ${ }^{16}$ More recently, C-H bond activation of methylene groups has been achieved using a triazole based ligand and $\mathrm{mCPBA},{ }^{17}$ and a bioinspired $\mathrm{Cu}(\mathrm{II})$ complex was used in the hydroxylation of benzene under mild conditions. ${ }^{18}$ With the aim of developing new, economically advantageous catalysts having increased sustainability for allylic oxidations, $\mathrm{Wu}$ and co-workers ${ }^{19}$ developed a $\mathrm{Cu}$ (II) 2-quinoxalinol salen complex which affected the oxidation of allylic species without the common additional requirements of high heat or long reaction times. In a subsequent study, such a catalyst was applied with TBHP acting as an oxidant, and the oxidation of a variety of olefin substrates was reported in high yields. ${ }^{20}$ The use of $\mathrm{Cu}(\mathrm{II})$ catalysts in the functionalization of organic structures both with and without the addition of peroxides has also recently been reviewed. ${ }^{21}$

The catalyst of interest in this work is $\mathrm{Cu}(\mathrm{II})(\mathrm{E})-6$-amino-7-((2-hydroxybenzylidene )amino)quinoxalin-2-ol, and was first reported in $2014 .^{22}$ This catalyst was developed to limit interference from free radical reactions, at the same time it was found to demonstrate 
excellent efficiency in allylic oxidation reactions. However prior gas-phase density functional theory study of the reaction mechanism resulted in a relatively high estimation of reaction barriers for the catalyzed oxidation process. For instance, the rate-determining step of $\mathrm{H}$ abstraction was reported to consume $43.7 \mathrm{kcal} / \mathrm{mol}$, while the final reaction step to release the final product (cyclohexenone) required $37.5 \mathrm{kcal} / \mathrm{mol}$. Especially, the important step to retrieve the initial catalytic structure was not reported by the gas-phase calculations. Thus, performing DFT-based molecular dynamics is an important task which enables us to unveil the full catalytic cycle. In recent years, DFT-based molecular dynamics methods ${ }^{23-25}$ have achieved sufficient computational efficiency to support broader application for the study of catalytic cycles that account for the ensemble and dynamic evolution of solvent and solutes. This method is a significant improvement over more widespread embedding methods attempting to include solvent effects by placing the solute of interest within a dielectric continuum. In the latter, direct solute-solvent interactions are not considered, which hampers the study of catalytic processes where the solvent may play a more prominant role. Further, the ensemble sampling of solute and solvent configurations can reveal important mechanistic features that are not observed when taking a more prescribed approach that involves a pre-defined reaction coordinate for the atoms of interest.

The current work demonstrates a new reaction scheme for the allylic oxidation of cyclohexene in acetonitrile, that has significantly lowered free energies for reaction relative to prior gas-phase DFT studies. Umbrella sampling with DFT-MD shows very good agreement with the previously proposed mechanism ${ }^{22}$ in the initial abstraction of allylic H-atom from cyclohexene and the formation of cyclohexenone. In addition, this corresponds well with an oxidation from $\mathrm{Cu}(\mathrm{II})$ to $\mathrm{Cu}(\mathrm{III})$ during the course of the $\mathrm{C}-\mathrm{H}$ bond activation. However, the final step of retrieving the catalyst resting state differs significantly. Specifically, the recovery of methyl peroxide $\left(\mathrm{CH}_{3} \mathrm{OO}-\right)$ attached to the $\mathrm{Cu}(\mathrm{II})$ site is revealed by our MD trajectory. Such a peroxide structure is capable of entering the next catalytic cycle. Meanwhile, the previous gas-phase calculations ${ }^{22}$ only reported the formation of methoxide 
$\left(\mathrm{CH}_{3} \mathrm{O}-\right)$ attached $\mathrm{Cu}(\mathrm{II})$. The new reaction scheme, with the participation of the ligand $\mathrm{N}$-atom as a source of $\mathrm{H}$-atoms, results in more sensible free energy barriers for the entire catalytic cycle that reflect experimental observations.

\section{Computational Details}

MD Simulation Protocol. The $\mathrm{Cu}(\mathrm{II})$ (E)-6-amino-7-((2-hydroxybenzylidene)amino)q uinoxalin-2-ol (1) complex is a simplified catalyst model with respect to the $\mathrm{Cu}$ (II) complex used in the previous experimental studies. ${ }^{22}$ In this model, two t-Butyl groups $\left(-\mathrm{C}\left(\mathrm{CH}_{3}\right)_{3}\right)$ on the quinoxalin-2-ol and salicylidene residues are replaced by - $\mathrm{H}$ because they are far from the reactive site, which consists $\mathrm{Cu}(\mathrm{II})$ and the attached methyl peroxide $\left(-\mathrm{OOCH}_{3}\right)$. Molecular structure $\mathbf{1}$ is very similar to that reported in the previous study, ${ }^{22}$ where two methyl groups are replaced by $\mathrm{H}$ to preserve computational cost. The second simulation model $\mathbf{2}$, which is further simplified by withdrawing an electron donating group, is studied in a later section to investigate how free energy would be affected. Catalysts $\mathbf{1}$ and $\mathbf{2}$ shown in Figure 1.
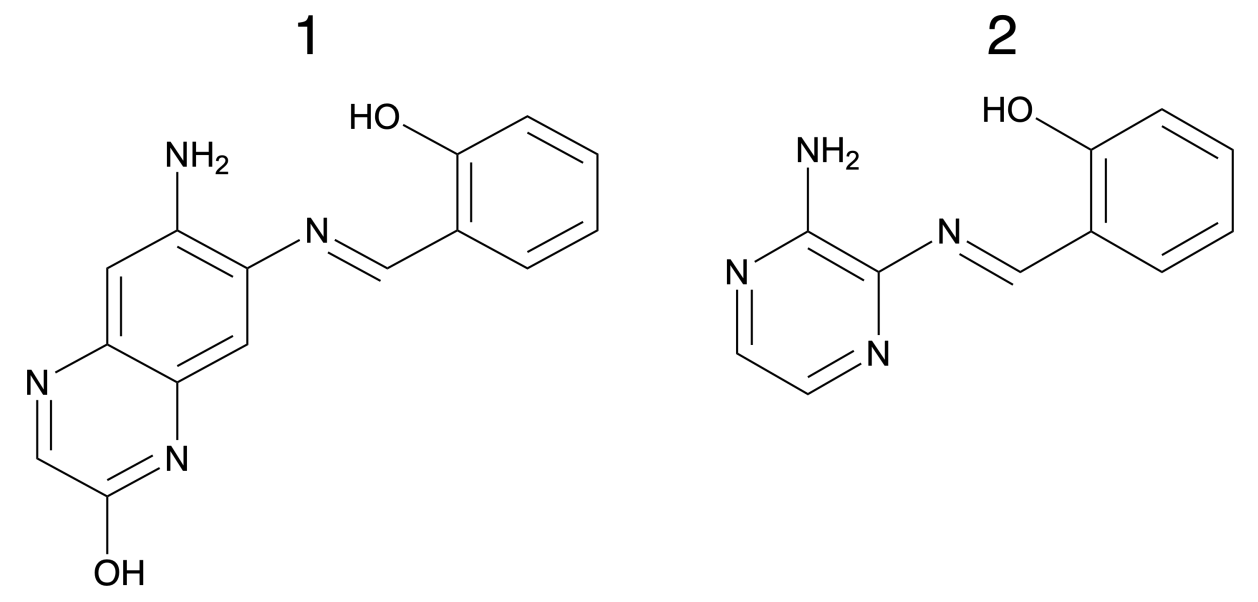

Figure 1: Molecular structures of the ligands used in the catalyst molecule 1 (E)-6-amino7-((2-hydroxybenzylidene)amino)quinoxalin-2-ol, and the abbreviated catalyst model 2 (E)2-[(3-aminopyrazin-2-yl)imino]methyl]-phenol.

The isolated structures $\mathbf{1}$ and $\mathbf{2}$ and reactants (cyclohexene and molecular methyl hydroperoxide) as well as the solvating molecules (i.e. acetonitrile as solvent) are initially 
optimized using the B3LYP functional ${ }^{26-28}$ and 6-31G(d) basis set ${ }^{29,30}$ in the Gaussian 16 package. ${ }^{31}$ Then, the catalyst, reactants, and 60 acetonitrile (357 atoms in total) are initialized by random insertion into a periodic cubic box using the Packmol code. ${ }^{32}$ The size of the periodic box with edge-length of $17.52 \AA$ is obtained as a result of system initialization using NPT-ensemble $a b$ initio MD. The density of the whole mixture is $0.77 \mathrm{~g} / \mathrm{cm}^{3}$. The low density relative to experimental bulk acetonitrile (density $=0.79 \mathrm{~g} / \mathrm{cm}^{3}$ ) is anticipated based upon the small simulation box size wherein about $20 \%$ of the volume is occupied by the solutes.

Born-Oppenheimer DFT-MD simulations are performed using the Quantum Espresso package, ${ }^{33}$ using the PBE functional ${ }^{34-36}$ with the DFT-D3, long-range London dispersion interaction classical interaction scheme proposed by Grimme, ${ }^{37}$ to provide empirical correction terms to the long-range interactions. The Rappe-Rabe-Kaxiras-Joannopoulos ultrasoft (RRKJUS) plane-wave basis set and pseudo-potential ${ }^{38-40}$ was employed for all participant atoms. To compromise with computational expense for such a large system, we use $\Gamma$-point calculations. A standard time step of 10 atomic time-units ( $0.242 \mathrm{fs}$ ) is used at every MD step, and the Verlet integration method $^{41}$ is employed to integrate the classical equations of motion. The NVT ensemble using velocity rescaling thermostat ${ }^{42}$ is enforced to allow thermal fluctuation around $350 \mathrm{~K}$, which resembles the actual temperature for carrying out the experiment in the previous study. ${ }^{22}$

Umbrella Sampling of the Catalytic Cycle. The umbrella sampling technique ${ }^{43-45}$ is used to examine the statistics of reaction coordinate in a particular reaction channel. In each bin, we apply a harmonic-bias potential to put a constraint on the chosen reaction coordinate. The reaction coordinate varies for each step in the catalytic cycle and is described in the Results and Discussion. Each harmonic potential adopts the form:

$$
V(\chi)=\frac{1}{2} \kappa\left(\chi-\chi_{e}\right)^{2}
$$


where $\kappa$ is the spring constant $\left(\mathrm{kcal} / \AA^{2}\right)$, and $\chi_{e}$ is the location for constraining the reaction coordinate $(\AA)$. To obtain good statistical data in umbrella sampling, the bin size chosen for umbrella sampling is $0.1 \AA$, and 200 DFT-MD steps are sampled in each bin.

From the biased MD data obtained at each step, the average distribution function can be computed statistically through a Boltzmann-weighted scheme:

$$
\left\langle\rho\left(\chi_{e}\right)\right\rangle=\frac{\int \delta\left(\chi_{e}-\chi\right) e^{-V(q) / k_{B} T} d q}{\int e^{-V(q) / k_{B} T} d q},
$$

In the above equation, $k_{B}$ is the Boltzmann constant, and $T$ is the chosen temperature (350 K) for simulation. This temperature is chosen in accordance with the actual experimental condition. ${ }^{22}$ Then, the potential of mean force (PMF) demonstrating the free-energy profile for a reaction along the user-defined internal coordinate $\chi$ can be calculated: ${ }^{46}$

$$
\omega(\chi)=-k_{B} T \ln (\langle\rho(\chi)\rangle)
$$

For the investigated reaction channels in this study, the PMF approximations which follow equations 2 and 3 are executed using the weighted-histogram analysis method (WHAM) as implemented by Grossfield. ${ }^{47,48}$

\section{Results and Discussion}

\section{Step 1: Abstraction of the Allylic H-atom from Cyclohexene}

As illustrated in Figure 2, allylic H-atom abstraction establishes a highly reactive C-site in cyclohexene. Within the umbrella sampling, two different abstraction steps were considered, where reaction coordinate consisted of either the allylic $\mathrm{H}$ site approach either $\mathrm{O}(1)$ or $\mathrm{O}(2)$ of the catalyst and establishing a new $\mathrm{O}-\mathrm{H}$ bond, and breaking the $\mathrm{O}-\mathrm{O}$ peroxide bond. The cyclohexene $\mathrm{H}$-site is initially placed $4.8 \AA$ from $\mathrm{O}(1)$ or $\mathrm{O}(2)$. Using a window size of $0.1 \AA$ with 200 MD equilibration steps at each distance, the distance is systematically decreased. 
The equilibration time was tested for its impact upon the statistical estimation of free energy, showing convergence at 200 steps. Figures S1 and S3 (Supporting Information) demonstrate the convergence test for free energy estimation of the $\mathrm{O}(1)-\mathrm{H}$ and $\mathrm{O}(2)-\mathrm{H}$ abstractions, while Figures S2 and S4 show the overlapping bins in umbrella sampling. In the initial stage having $r_{(O 1)-H}$ or $r_{(O 2)-H}(\geq 2.7 \AA)$, a force constant for the harmonic bias of $(\kappa=50$ $\mathrm{kcal} / \mathrm{mol} \AA^{2}$ ) is employed, which is increased to $100 \mathrm{kcal} / \mathrm{mol} \AA^{2}$, and at the transition state of new O-H bond formation (around $1.2 \AA$ ), a high force constant of $400 \mathrm{kcal} / \mathrm{mol} \AA^{2}$ is used. In fact, it is practical to perform manual tuning of harmonic constants during the process of umbrella sampling to enforce good overlapping bins. ${ }^{49}$ For our reaction of interest, the chemical interaction experiences weak (long-range) bonding at large reaction coordinate, then undergoes the formation of an $\mathrm{O}-\mathrm{H}$ covalent bond at low reaction coordinate. As a result, the use of small $\kappa$ for weak bonding and large $\kappa$ for strong bonding would guarantee that we obtain good overlapping bins in umbrella sampling. As shown in Figure 2, the PMF curve of the $\mathrm{O}(1)-\mathrm{H}$ channel shows a free energy barrier of $12.1 \pm 0.2 \mathrm{kcal} / \mathrm{mol}$, which is more favorable than the $\mathrm{O}(2)-\mathrm{H}$ channel $(15.5 \pm 0.3 \mathrm{kcal} / \mathrm{mol})$. This favorability of the $\mathrm{O}(1)-\mathrm{H}$ reaction channel in our investigation is in good agreement with the theoretical mechanism proposed in the previous work. ${ }^{22}$ However, the previous gas-phase calculations predicted a potential energy barrier of $43.7 \mathrm{kcal} / \mathrm{mol}$ for the $\mathrm{O}(1)-\mathrm{H}$ reaction channel, much higher than our energetic scheme in the solvation phase.

Following the first reaction channel, an -OH residue is established at the $\mathrm{O}(1)$ site, which bonds directly to $\mathrm{Cu}(\mathrm{II})$, while $\mathrm{CH}_{3} \mathrm{O}(2)$. becomes a radical along with the resultant radical cyclohexene. Interestingly, the neighboring $-\mathrm{NH}_{2}$ group plays a role as a $\mathrm{H}$-atom source to stabilize the radical site. Within the first reaction channel, $\mathrm{CH}_{3} \mathrm{O}(2) \cdot$ quickly attacks $-\mathrm{NH}_{2}$ to abstract an $\mathrm{H}$ atoms and produce methanol. This is a fast and spontaneous process that can be observed very shortly after the $\mathrm{O}(1)-\mathrm{O}(2)$ dissociation.

In the second reaction channel, it is surprising that the final outcome is similar to the outcome of the first reaction channel. In this scheme, the alcohol residue is now established 

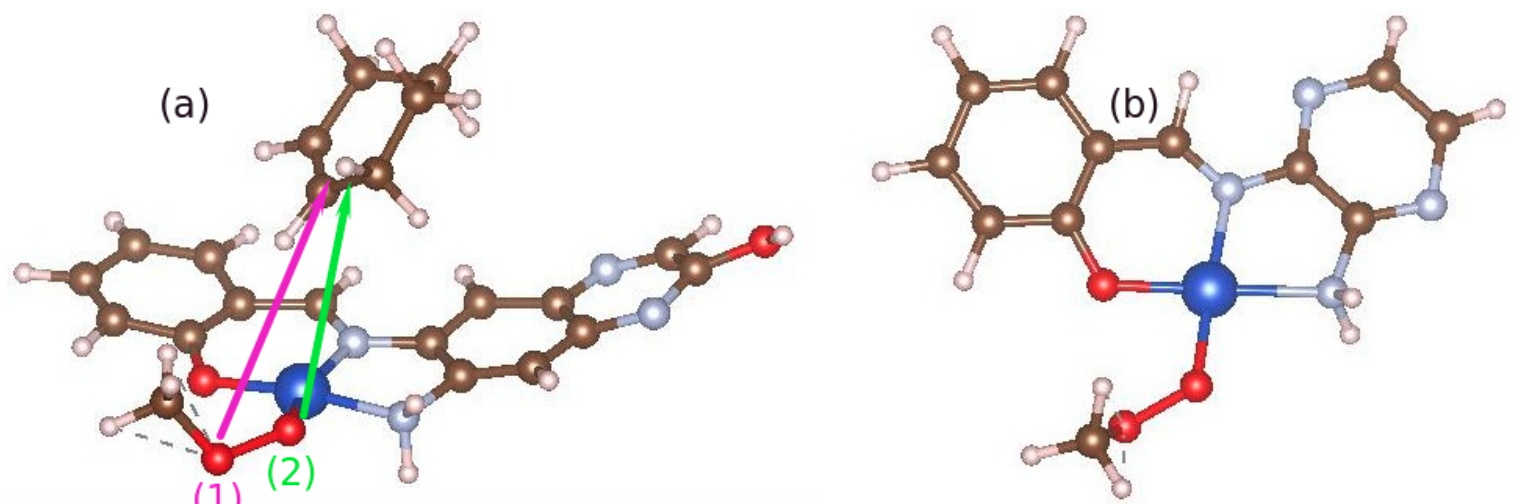

(1)

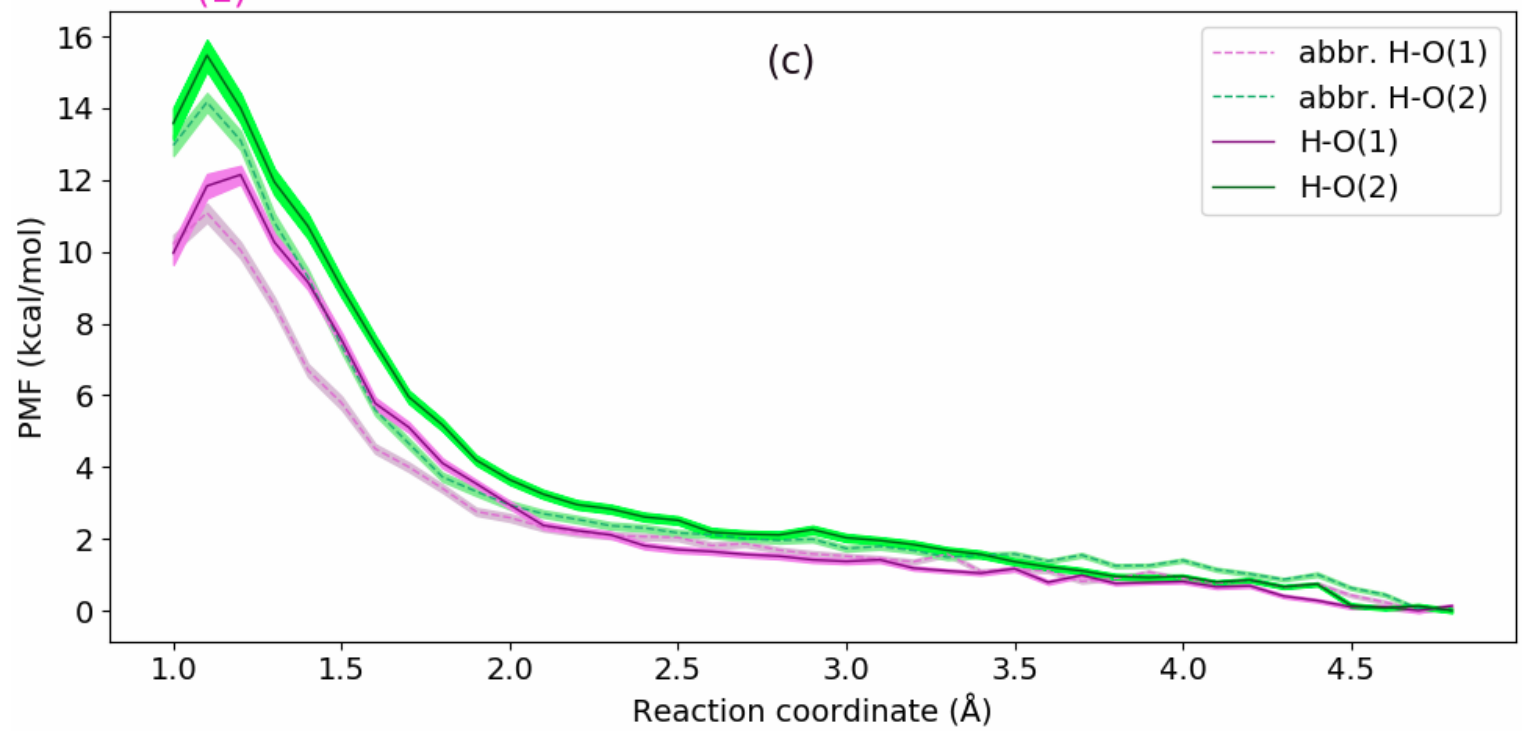

Figure 2: (a) The reaction model with two proposed channels for allylic $\mathrm{H}$ abstraction by $\mathrm{O}(1)$ and $\mathrm{O}(2)$, (b) The abbreviated catalyst model, (c) The PMF curves depicting $\mathrm{H}$ abstraction by $\mathrm{O}(1)$ and $\mathrm{O}(2)$ in the original catalyst (solid lines) or the abbreviated catalyst (dashed lines). Color codes for atomic representation: $\mathrm{Cu}$ (deep blue), C (brown), O (red), N (light blue), hydrogen (white).

at the $\mathrm{O}(2)$ site. Methanol is produced directly on a first-hand basis, while the $\mathrm{O}(1)$ site now becomes a strong radical. To achieve stabilization, $\mathrm{O}(1)$ quickly attracts $\mathrm{H}$ from the nearby $-\mathrm{NH}_{2}$ and becomes $-\mathrm{O}(1)-\mathrm{H}$ attached to the $\mathrm{Cu}$ site. Therefore, both reaction channels finally lead to the formation of methanol and $\mathrm{Cu}-\mathrm{O}-\mathrm{H}$, and the dehydrogenation of $-\mathrm{NH}_{2}$ to -NH. Due to this transformation, the $\mathrm{Cu}-\mathrm{N}$ bond is no longer a coordination bond, but it indeed becomes an ionic bond. Such a unique dehydrogenation behavior can be observed in this study thanks to the advantage of MD simulation, which enables us to reveal the full portrait of the chemical transformation process. As we will discuss in a later section, the 
newly-established -NH group can be further dehydrogenated, or recover an H-atom to revert back to $-\mathrm{NH}_{2}$. This ability of the $-\mathrm{NH}_{2}$ to act as a hydrogen source is the driving factor that helps to recover the initial catalyst. Last but not least, due to the dehydrogenation of the "magic" $\mathrm{N}$ site, the oxidation state of $\mathrm{Cu}(\mathrm{II})$ is altered to $\mathrm{Cu}(\mathrm{III})$, which was also observed in the previous experiment. ${ }^{22}$ In fact, we verify the change in the Mulliken charge of $\mathrm{Cu}$ by performing Gaussian calculations for the original catalyst structure and the radical structure after the $\mathrm{H}$ abstraction. The result indicates that the $\mathrm{Cu}$ site becomes more positive (Mulliken charge changes from 0.78 to 0.86), while the Mulliken charge of $\mathrm{N}$ remains unchanged (-0.69). This offers a theoretical evidence for the switch in $\mathrm{Cu}$ oxidation state. The summary of the competition between the two reaction channels leading to the same product is shown in Scheme 1.

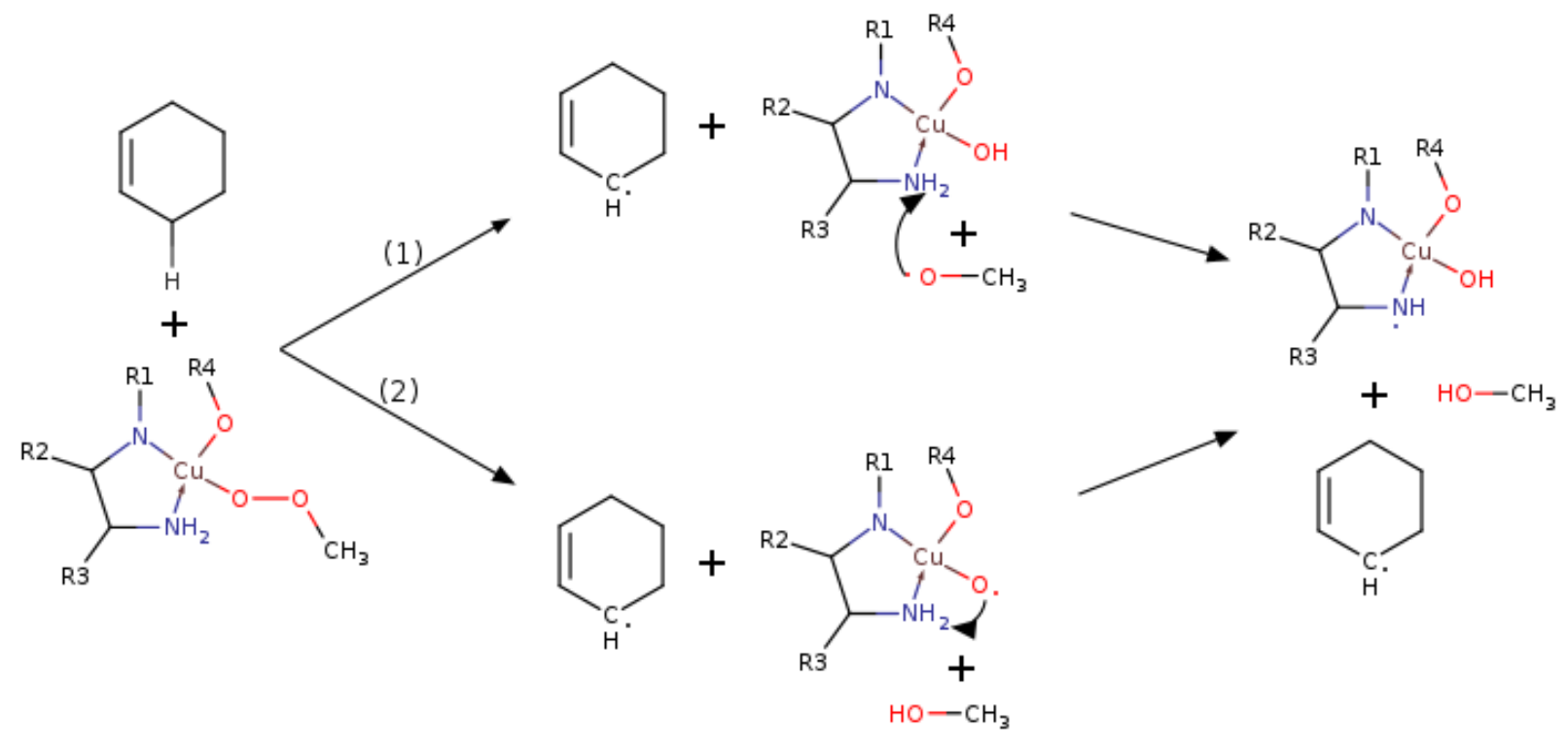

Scheme 1: After the peroxide dissociation, two reaction branches lead to the same formation of cyclohexene radical and methanol.

The reaction scheme is verified using an abbreviated catalyst model depicted as compound 2 in Figures 1(b) and 2(b). This allows to speed up calculations and also focus on the active site of the catalyst, namely the nitrogen and copper atoms. The umbrella sampling is done for both reaction channels as it has been executed for the original catalyst. Interestingly, both 
free energy barriers given by the abbreviated catalyst (represented by the dashed curves) are found to be lower than the that given by the original catalyst. Specifically, the new $\mathrm{O}(1)-\mathrm{H}$ abstraction consumes $11.1 \pm 0.2 \mathrm{kcal} / \mathrm{mol}$, while the new $\mathrm{O}(2)-\mathrm{H}$ abstraction consumes 14.2 $\pm 0.3 \mathrm{kcal} / \mathrm{mol}$.

\section{Step 2: The formation of cyclohexenone}

The second step of the reaction takes place establishing the desired product when the highly reactive cyclohexene radical is oxidized by molecular oxygen in the solvent. To initiate the set-up for this process, we allow $\mathrm{O}_{2}$ to approach the radical site on cyclohexene from a distance of $4.0 \AA$ and perform umbrella sampling to investigate the binding stage between $\mathrm{O}_{2}$ and radical cyclohexene. It is found, however, soon along the umbrella sampling process, that $\mathrm{O}_{2}$ establishes a bonding interaction with the radical $\mathrm{C}$ site at around $3.2 \AA$. The fluctuation in PMF during this process with insignificant free energy can be regarded as thermal fluctuation within the liquid phase. After that, the radical cyclohexene- $\mathrm{O}_{2}$ system is allowed to conduct thermal vibration at $350 \mathrm{~K}$, and then we perform the next umbrella sampling step leading to the formation of cyclohexenone.

As shown in Figure 3, while one $\mathrm{O}$ forms a $\sigma$ bond with the radical $\mathrm{C}$ site, the second $\mathrm{O}$ approaches the remaining allylic $\mathrm{H}$ site to form a new $\mathrm{O}-\mathrm{H}$ bond. Of note, the first arrangement of $\mathrm{O}-\mathrm{O}-\mathrm{C}-\mathrm{H}$ adopts a trans conformation. Before the reaction takes place, the system is equilibrated at $350 \mathrm{~K}$, and the initial $\mathrm{O}-\mathrm{H}$ distance is found around $3.2 \AA$. In the umbrella sampling process, the $\mathrm{O}-\mathrm{O}$ bond rotates around the $\mathrm{O}-\mathrm{C}$ axis in order to approach the targeted $\mathrm{H}$ site. When the $\mathrm{O}-\mathrm{H}$ distance is $2.4 \AA$, the $\mathrm{O}-\mathrm{O}-\mathrm{C}-\mathrm{H}$ adopts a cis conformation. To transform from trans to cis, it takes only about $0.8 \mathrm{kcal} / \mathrm{mol}$. Then, from the cis conformation, the free energy starts to grow more rapidly toward the product

site. When the $\mathrm{O}-\mathrm{H}$ distance is around $1.5 \AA$, we observe the free energy barrier of 8.2 $\pm 0.2 \mathrm{kcal} / \mathrm{mol}$. The verification of free energy convergence and overlapping of umbrellasampling bins for this product formation step is shown in Figures S5 and S6. In the last 
umbrella sampling step at $1.4 \AA$, the newly formed $\cdot \mathrm{OH}$ is established, and departs from the cyclohexene system to yield cyclohexanone.

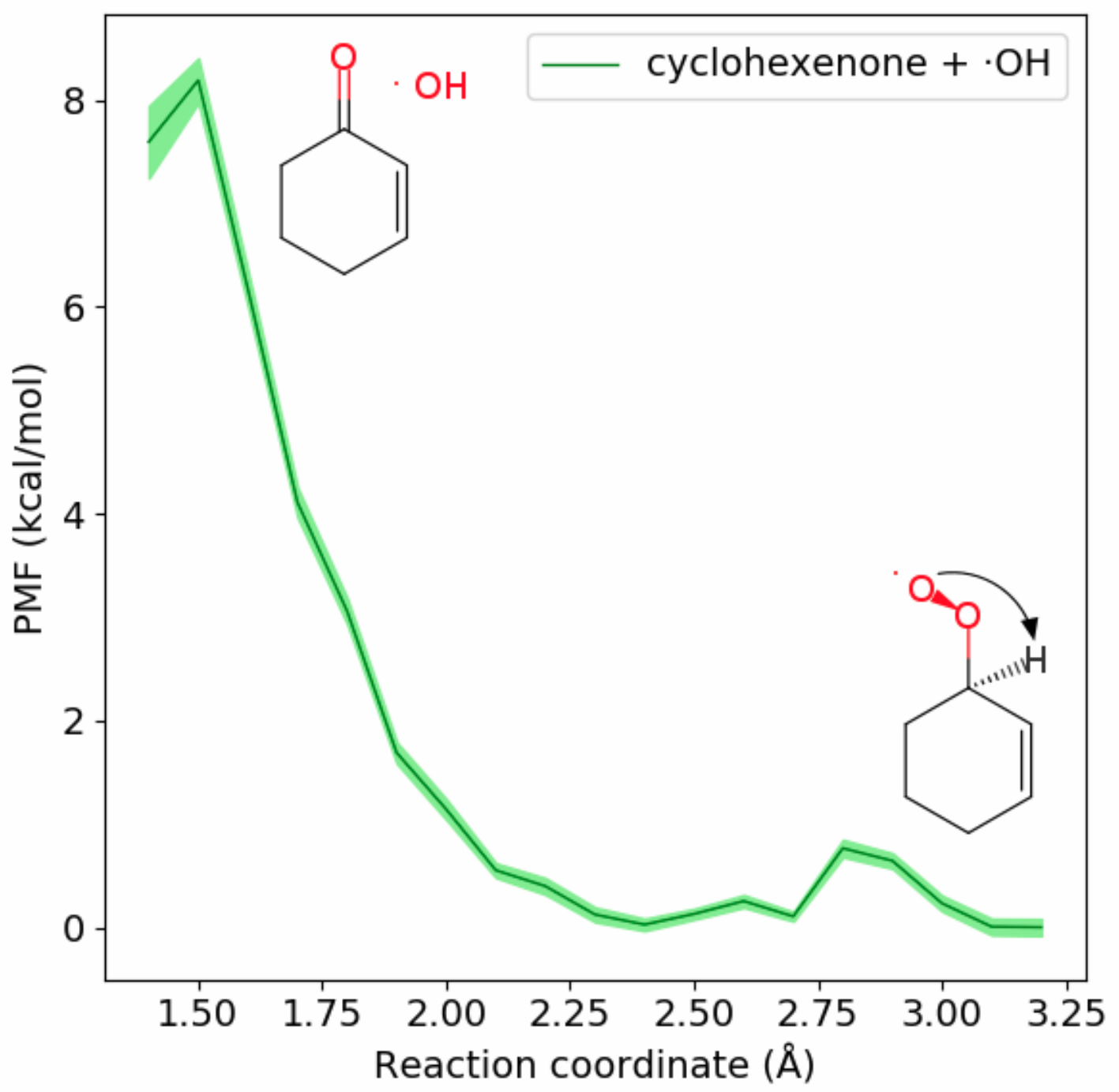

Figure 3: PMF of the $\mathrm{O}-\mathrm{H}$ combination leading to the formation of cyclohexenone and $\cdot \mathrm{OH}$ radical. At the last sampling point, the final product is formed with a free energy barrier of $8.2 \pm 0.2 \mathrm{kcal} / \mathrm{mol}$.

The $\mathrm{OH}$ radical is a highly reactive species, which possesses a significant tendency to react with the surrounding molecules. In fact, a hydrogen exchange can occur with fresh-made methanol, or with an available solvent molecule (in this case, acetonitrile). Indeed, we observe in our benchmark calculations that the two processes occur very rapidly and barrierlessly. 
The products of those two processes are actually observed in our MD trajectories at $350 \mathrm{~K}$ without any biases applied to the chemical species.

In the reaction with methanol, hydroxymethyl radical $\left(\mathrm{CH}_{3} \mathrm{O} \cdot\right)$ is produced as a consequence. Then, because $\mathrm{CH}_{3} \mathrm{O}$ - is also very reactive, it quickly grabs a hydrogen from the "magic" hydrogen-donating N (as labelled in Figure 2), and is converted back to its stable state $\mathrm{CH}_{3} \mathrm{OH}$ while leaving $\cdot \mathrm{NH}$ as the new radical site. Therefore, this process can be regarded as an indirect hydrogen transfer from the "magic" $\mathrm{N}$ to $\cdot \mathrm{OH}$ radical. In the second observable reaction, $\mathrm{CH}_{3} \mathrm{O}$. also grabs one $\mathrm{H}$ atom from $\mathrm{CH}_{3} \mathrm{CN}$, and turns the solvent molecule to be radical at the $\mathrm{N}$ site. The observed reaction scheme of $\cdot \mathrm{OH}$ radical is presented in Scheme 2.

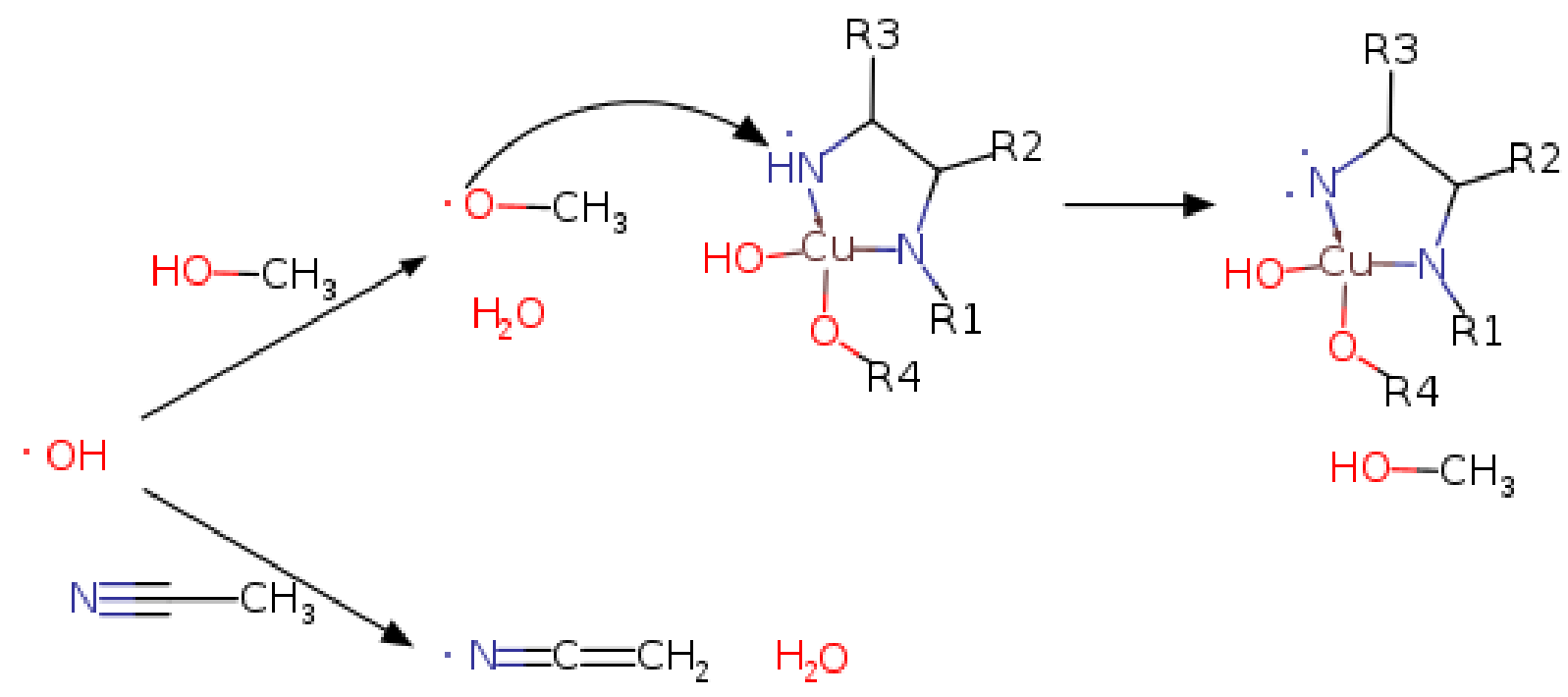

Scheme 2: Activity of $\cdot \mathrm{OH}$ radical in the solution.

\section{Step 3: Recovery of the initial catalyst}

To quickly summarize the reaction stage at this point, we have obtained the desired product, i.e. cyclohexenone; at the same time, two side products are established: $\mathrm{H}_{2} \mathrm{O}$ and $\mathrm{CH}_{3} \mathrm{OH}$. For the purpose of recovering the original structure of the catalyst, we investigated the assumption that the first reaction branch in Scheme 2 is more prioritized. As a result, the 
"magic" hydrogen-donating $\mathrm{N}$ site has lost two $\mathrm{H}$ atoms toward $\mathrm{O}(1)$ and $\mathrm{O}(2)$ as shown in Figure 4. Even though methanol is already established, it is found that the OH group from the methanol still retains a bond with the "magic" N. Interestingly, in the context of chemical interaction, $\mathrm{H}(2)$ seems to be shared by both $\mathrm{N}$ and $\mathrm{O}(2)$. Meanwhile, $\mathrm{H}(1)$ is only binding to $\mathrm{O}(1)$ and retains a non-bonding distance from $\mathrm{N}$.

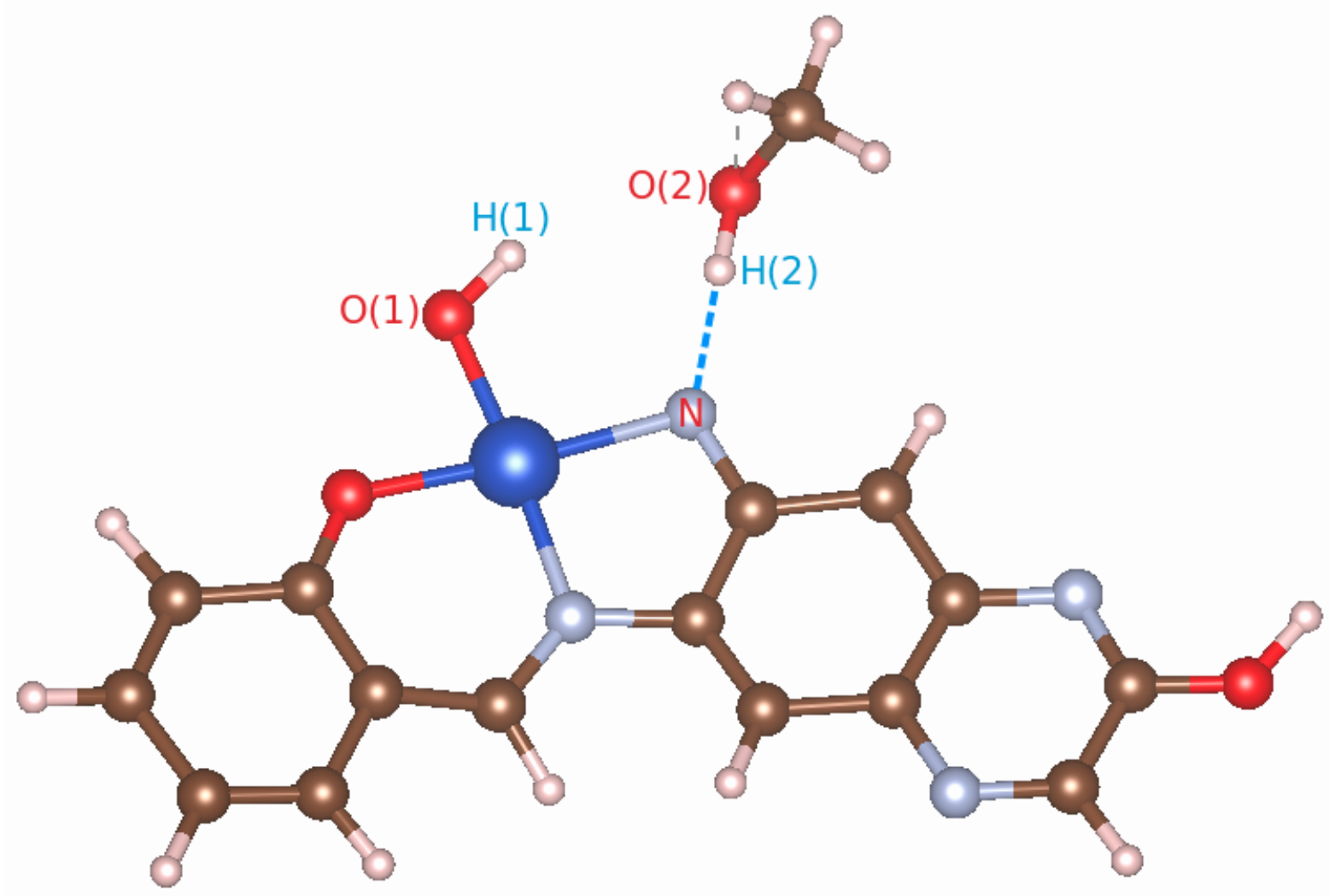

Figure 4: Structure of the catalyst after the final product is formed. For clarity, all solvent molecules, cyclohexenone, and $\mathrm{H}_{2} \mathrm{O}$ are discarded. The "magic" hydrogen-donating $\mathrm{N}$ now loses both $\mathrm{H}$ atoms to $\mathrm{O}(1)$ and $\mathrm{O}(2)$; however, $\mathrm{CH}_{3} \mathrm{O}(2)-\mathrm{H}(2)$ still establishes a long-range interaction with $\mathrm{N}$.

To verify the capability of donating $\mathrm{H}(1)$ back to the $\mathrm{N}$ atom, we subsequently perform an umbrella sampling, in which the N-H(1) distance is taken as the collective coordinate. The catalyst structure in Figure 4 is equilibrated in the acetonitrile as solvent before executing the umbrella sampling process. The first few steps of umbrella sampling shows that the structure attains its lowest free energy state when the $\mathrm{N}-\mathrm{H}(1)$ distance resides in the range of 2.3-2.7 $\AA$. Beyond $2.3 \AA$, the free energy is elevated with a small slope, then the free energy increases 
more vigorously when the reaction coordinate reaches $1.7 \AA$. Following this, the process of $\mathrm{H}$ transfer starts to occur. This reaction step is different from other umbrella sampling steps seen in this study, i.e. while $\mathrm{H}(1)$ is transferred to $\mathrm{N}$, the $\mathrm{O}(1)$ site becomes radical. At the $\mathrm{N}-\mathrm{H}(1)$ distance of $1.16 \AA, \mathrm{H}(1)$ is transferred to $\mathrm{N}$ with a free energy barrier of $10.7 \pm 0.2$ $\mathrm{kcal} / \mathrm{mol}$. The verification of free energy convergence and overlapping of umbrella-sampling bins for this hydrogen migration step is shown in Figures S7 and S8. After the last umbrella sampling step, we allow the system to equilibrate, and $\mathrm{H}(1)$ actually resides at the $\mathrm{N}$ site. The PMF profile of this process is shown in Figure 5. It should be noted that the radical $\mathrm{N}$ site becomes more stabilized after it establishes a covalent bond to $\mathrm{H}(1)$. As mentioned earlier, both $\mathrm{N}$ and the methoxy group $\left(\mathrm{CH}_{3} \mathrm{O}\right)$ share the common $\mathrm{H}(2)$. After $\mathrm{H}(1)$ has been transferred to $\mathrm{N}$, we observe the weakening of $\mathrm{N}-\mathrm{H}(2)$ interaction. As a result, right after the $\mathrm{N}-\mathrm{H}(1)$ bond is established, $\mathrm{H}(2)$ has a tendency to break apart from the magic "N" site and consequently, methanol is released as a free molecule.

The above simulation of $\mathrm{N}-\mathrm{H}(1)$ recombination allows us to formulate a new perspective about the radicalization of $\mathrm{O}(1)$ and $\mathrm{O}(2)$ sites. Those two radical sites can be stabilized by the $\mathrm{H}$ donation process from their neighboring "magic" $\mathrm{N}$. When it comes back to the re-establishment of the initial catalyst, the proton-donating $\mathrm{N}$ site is capable of accepting $\mathrm{H}$ back with an affordable free energy $(8.6 \mathrm{kcal} / \mathrm{mol})$. Thus, the continual accepting-donating behavior of the $\mathrm{N}$ site leads to the recyclability of the catalyst in this study.

Having proven that $\mathrm{H}(1)$ is capable of migrating back to the "magic" $\mathrm{N}$ site, we now construct the subsequent step to recover the initial catalyst by enforcing $\mathrm{O}(1)$ and $\mathrm{O}(2)$ to revive their peroxide connection. At this point, the $\mathrm{O}(1)-\mathrm{O}(2)$ distance is used as the reaction coordinate, and we subsequently perform an umbrella sampling to retrieve the peroxide connection. Even though $\mathrm{N}$ wins its $\mathrm{H}(1)$ back from $\mathrm{O}(1)$, it still slightly holds a loose connection with $\mathrm{H}(2)$ from the free methanol molecule. The system is allowed to equilibrate, which sets the O-O distance in the system to be around 3.5 A. After 19 umbrella sampling steps ( step size $=0.1 \AA$ ), the system seems to be trapped in a local minimum 


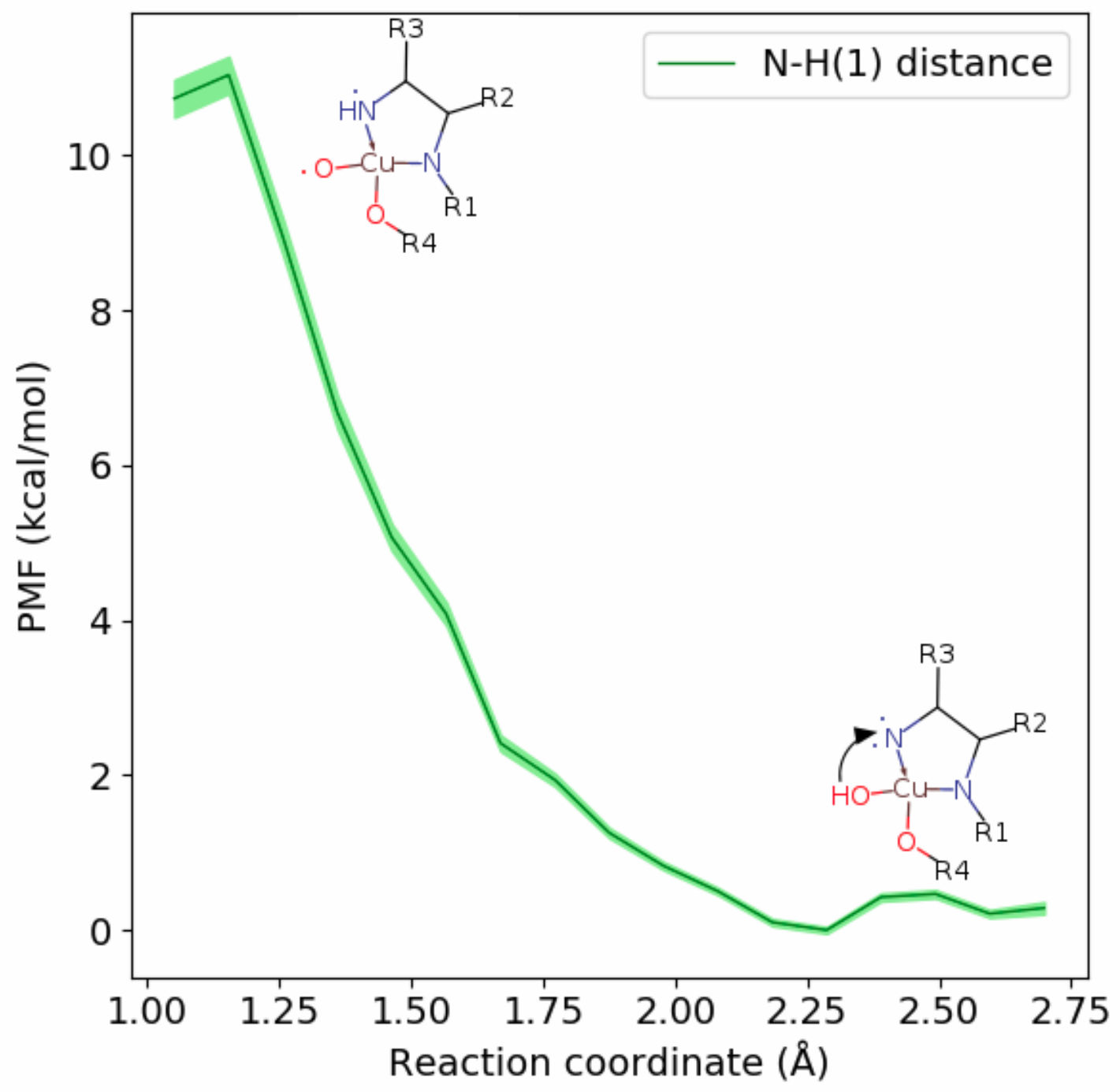

Figure 5: $\mathrm{PMF}$ of the $\mathrm{N}-\mathrm{H}(1)$ bond formation leading to the establishment of $\mathrm{O}(1)$ radical site. The free energy barrier of this process is $10.7 \pm 0.2 \mathrm{kcal} / \mathrm{mol}$.

where the peroxide O-O distance is around $1.7 \AA$, as shown in Figure 6(a). Later, the actual minimum for the O-O peroxide bond is located around $1.5 \AA$. The free energy barrier of this process is determined as $7.6 \pm 0.5 \mathrm{kcal} / \mathrm{mol}$, which is found around the O-O distance of 1.9 A. The verification of free energy convergence and overlapping of umbrella-sampling bins for the O-O bond formation is shown in Figures S9 and S10. Continuing to sample toward the O-O equilibrium distance around 1.4-1.5 $\AA$, we find the methyl peroxide molecule $\left(\mathrm{CH}_{3} \mathrm{OOH}\right)$ is established with $\mathrm{O}(1)$ still bonding to the $\mathrm{Cu}$ site via a coordination bond. At this point, 
the $\mathrm{O}-\mathrm{O}$ bond may either undergo dissociation again to release radical $\mathrm{CH}_{3} \mathrm{O}$, which can re-enter the catalytic cycle to radicalize the allylic $\mathrm{C}$ site on a new cyclohexene molecule. Otherwise, $\mathrm{H}(2)$ is transferred from the peroxide structure to the "magic" $\mathrm{N}$ site to restore the original catalyst structure.

The final umbrella sampling process is carried out with the recovery of the catalyst, in which we investigate the return of $\mathrm{H}(2)$ to $\mathrm{N}$. After the $\mathrm{O}(1)-\mathrm{O}(2)$ peroxide bond is establish, the whole system is then allowed to equilibrate at $350 \mathrm{~K}$. The equilibrated N-H distance after this process is just $2.3 \AA$, and it would take relatively short umbrella sampling process to reach the final structure, which is our desired catalyst. As shown in Figure 6(b), while H(2) moves toward to $\mathrm{N}$ site from the distance of $2.3 \AA$, the free energy drops slightly at $2.1 \AA$, which is the minimum point of this process. At the $\mathrm{N}-\mathrm{H}$ distance around $1.3 \AA$, the free energy barrier shows up as $4.5 \pm 0.1 \mathrm{kcal} / \mathrm{mol}$. After overcoming the harmonic sampling step around $1.2 \AA$, the original structure of catalyst is finally recovered. The verification of free energy convergence and overlapping of umbrella-sampling bins for this final catalyst recovery step is shown in Figures S11 and S12.

The overall reaction mechanism observed by umbrella sampling MD in this study is presented in Scheme 3. It should be noted that we only present the primary reaction channels with favorable free energies barriers in the scheme. Overall, a water molecule is obtained as a side product beside the targeted product, cyclohexenone. According to this cycle, at the completion of reaction, the catalyst can be fully recovered, which is revealed by our umbrella sampling MD data.

\section{Summary}

In this study, we perform a theoretical investigation of the allylic oxidation of cyclohexenone

through a catalytic process promoted by the $\mathrm{Cu}(\mathrm{II})$ complex reported in a previous study. ${ }^{22}$ Under the solvation effect of acetonitrile, the free energy barrier of $12.1 \pm 0.2 \mathrm{kcal} / \mathrm{mol}$ is 


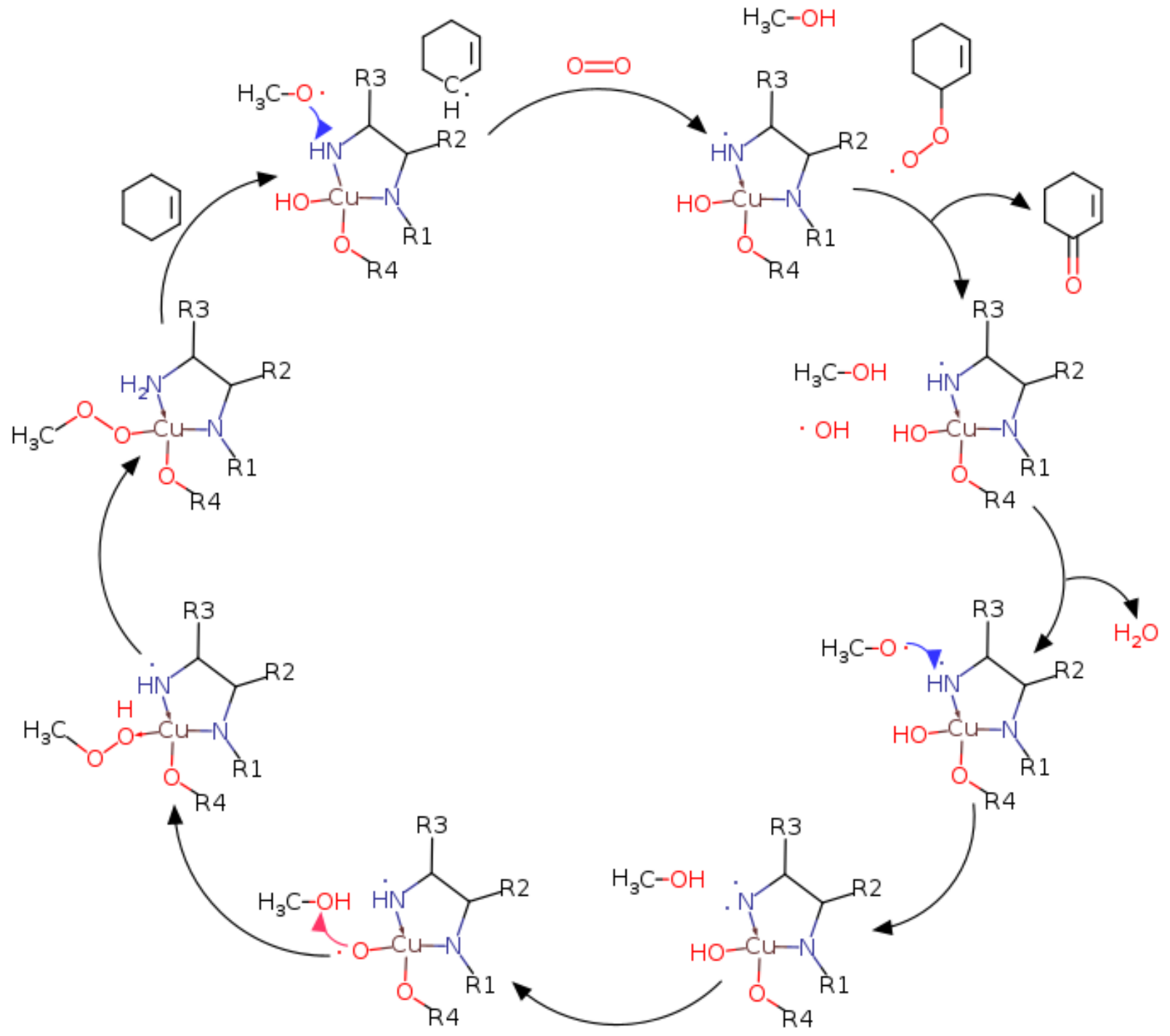

Scheme 3: The overall allylic oxidation scheme observed by umbrella sampling DFT-MD. 

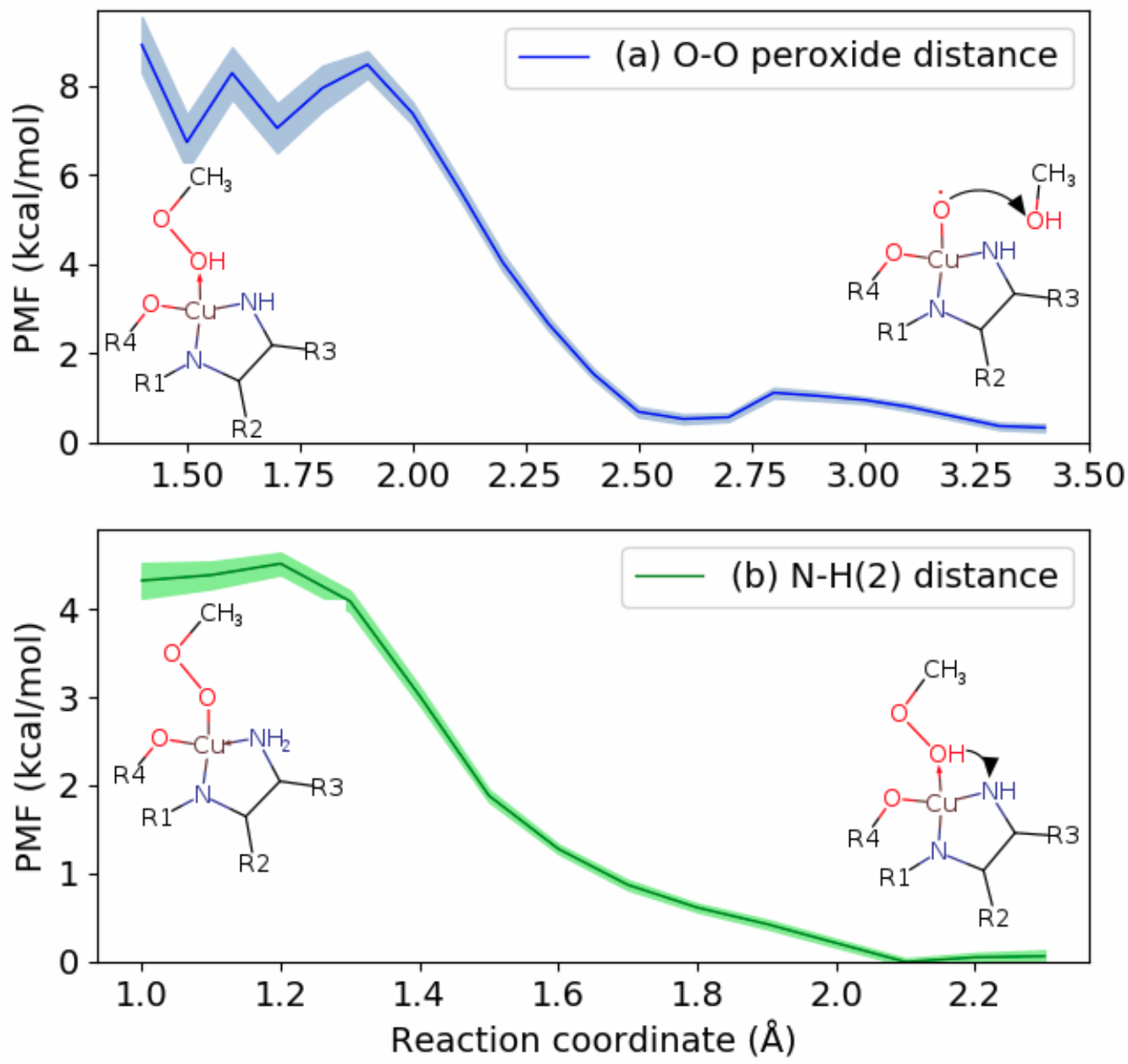

Figure 6: (a) PMF along the $\mathrm{O}(1)-\mathrm{O}(2)$ distance to re-establish the peroxide bond showing a free energy barrier of $7.6 \pm 0.5 \mathrm{kcal} / \mathrm{mol}$, (b) PMF of the $\mathrm{N}-\mathrm{H}$ distance to recover the initial catalyst showing a free energy barrier of $4.5 \pm 0.1 \mathrm{kcal} / \mathrm{mol}$.

reported for the initial step of simultaneous peroxide dissociation and cleavage of the allylic $\mathrm{H}$ in cyclohexene. This free energy barrier is actually much lower than the gas-phase reaction barrier $(43.7 \mathrm{kcal} / \mathrm{mol})$ reported by Li et al. ${ }^{22}$ Then, the desired product (cyclohexenone) is established in a subsequent step in the reaction between radical cyclohexene and molecular oxygen is observed to release $\cdot \mathrm{OH}$ as a byproduct.

In the later stage of the reaction, we also show that $\cdot \mathrm{OH}$ enters the reaction cycle to 
abstract one $\mathrm{H}$ atom from the proton-donating $\mathrm{N}$ site, as shown in Scheme 2. Finally, the $\mathrm{Cu}(\mathrm{II})$ catalyst can be recovered as a result of multi-step $\mathrm{CH}_{3} \mathrm{O}(2) \mathrm{H}$ and $-\mathrm{O}(1) \mathrm{H}$ reductions. In this last stage, the first and second $\mathrm{H}$ back-donating transfers to the "magic" amino site are observed and possess free energy barriers of $8.6 \mathrm{kcal} / \mathrm{mol}$ and $5.2 \mathrm{kcal} / \mathrm{mol}$, respectively, while the re-establishement of the O-O peroxide bond consumes a free energy of $8.2 \mathrm{kcal} / \mathrm{mol}$. The deprotonation/protonation of the "magic" amino group is the main factor leading to smooth recovery of the initial catalyst, thus reinforces catalytic efficiency.

Overall, we observe that the very first step of O-O dissociation leading to the abstraction of allylic $\mathrm{H}$ from cyclohexene is the highest energy consumption step. However, our statistical MD evidence demonstrates that the reaction barrier for this rate-limiting step is much lower than that reported by gas-phase optimization in the previous study $(43.7 \mathrm{kcal} / \mathrm{mol})^{22}$ thanks to the solvation effect of acetonitrile. In future work, we look forward to applying this method to explore the effects of other types of solvents, and learn how it may affect the reaction outcome in terms of both free energy and reaction byproducts. This is potentially one tool in providing improved descriptions of the kinetic reactivity of metal complexes in catalytic systems.

\section{Acknowledgement}

We are thankful to the computational resource from the Center for Institutional Research Computing, Washington State University (Pullman, WA) and the Center for Computational Materials Science, Tohoku University (Tohoku, Japan).

\section{Supporting Information Available}

In the Supporting Information, we demonstrate supplementary figures showing that our umbrella sampling gives appropriate statistical data. 


\section{References}

(1) Danishefsky, S.; Kahn, M. Regiospecificity in the Diels-Alder reactions of an enedione. Tetrahedron Letters 1981, 22, 489 - 492.

(2) Ballini, R.; Bosica, G. A direct method for the synthesis of polyfunctionalized unsaturated carbonyl derivatives by Michael addition of nitroalkanes to enediones with the help of DBU. Tetrahedron 1995, 51, 4213 - 4222 .

(3) Salva, J.; Faulkner, D. J. Metabolites of the sponge Strongylophora durissima from Maricaban Island, Philippines. The Journal of Organic Chemistry 1990, 55, 19411943.

(4) Ballini, R.; Bosica, G. The Michael reaction of nitroalkanes with conjugated enones in aqueous media. Tetrahedron Letters 1996, 37, 8027 - 8030.

(5) Liu, Y.; Liu, X.; Wang, M.; He, P.; Lin, L.; Feng, X. Enantioselective Synthesis of 3,4-Dihydropyran Derivatives via Organocatalytic Michael Reaction of ,-Unsaturated Enones. The Journal of Organic Chemistry 2012, 77, 4136-4142, PMID: 22432769.

(6) Nakamura, A.; Nakada, M. Allylic Oxidations in Natural Product Synthesis. Synthesis 2013, 45, 1421-1451.

(7) Weidmann, V.; Maison, W. Allylic Oxidations of Olefins to Enones. Synthesis 2013, 45, 2201-2221.

(8) Miller, R. A.; Li, W.; Humphrey, G. R. A ruthenium catalyzed oxidation of steroidal alkenes to enones. Tetrahedron Letters 1996, 37, 3429 - 3432.

(9) Salvador, J.; Sáe Melo, M.; Campos Neves, A. Copper-catalysed allylic oxidation of 5-steroids by t-butyl hydroperoxide. Tetrahedron Letters 1997, 38, 119 - 122. 
(10) Yu, J.-Q.; Wu, H.-C.; Corey, E. J. Pd(OH)2/C-Mediated Selective Oxidation of Silyl Enol Ethers by tert-Butylhydroperoxide, a Useful Method for the Conversion of Ketones to ,-Enones or -Silyloxy-,-enones. Organic Letters 2005, 7, 1415-1417.

(11) Fousteris, M. A.; Koutsourea, A. I.; Nikolaropoulos, S. S.; Riahi, A.; Muzart, J. Improved chromium-catalyzed allylic oxidation of 5-steroids with t-butyl hydroperoxide. Journal of Molecular Catalysis A: Chemical 2006, 250, 70 - 74.

(12) Silvestre, S. M.; Salvador, J. A. Allylic and benzylic oxidation reactions with sodium chlorite. Tetrahedron 2007, 63, 2439 - 2445.

(13) McLaughlin, E. C.; Choi, H.; Wang, K.; Chiou, G.; Doyle, M. P. Allylic Oxidations Catalyzed by Dirhodium Caprolactamate via Aqueous tert-Butyl Hydroperoxide: The Role of the tert-Butylperoxy Radical. The Journal of Organic Chemistry 2009, 74, 730-738.

(14) Yao, B.; Wang, D.-X.; Huang, Z.-T.; Wang, M.-X. Room-temperature aerobic formation of a stable aryl-Cu(iii) complex and its reactions with nucleophiles: highly efficient and diverse arene $\mathrm{C}-\mathrm{H}$ functionalizations of azacalix[1]arene[3]pyridine. Chem. Commun. 2009, 2899-2901.

(15) Wang, H.; Wang, Y.; Liang, D.; Liu, L.; Zhang, J.; Zhu, Q. Copper-Catalyzed Intramolecular Dehydrogenative Aminooxygenation: Direct Access to FormylSubstituted Aromatic N-Heterocycles. Angewandte Chemie International Edition 2011, 50, 5678-5681.

(16) Pirovano, P.; Magherusan, A. M.; McGlynn, C.; Ure, A.; Lynes, A.; McDonald, A. R. Nucleophilic Reactivity of a Copper(II)-Superoxide Complex. Angewandte Chemie International Edition 2014, 53, 5946-5950.

(17) Abazid, A. H.; Clamor, N.; Nachtsheim, B. J. An Enantioconvergent Benzylic Hydrox- 
ylation Using a Chiral Aryl Iodide in a Dual Activation Mode. ACS Catalysis 2020, 10, 8042-8048.

(18) Muthuramalingam, S.; Anandababu, K.; Velusamy, M.; Mayilmurugan, R. Benzene Hydroxylation by Bioinspired Copper(II) Complexes: Coordination Geometry versus Reactivity. Inorganic Chemistry 2020, 59, 5918-5928.

(19) Wu, X.; Gorden, A. E. V. 2-Quinoxalinol Salen Copper Complexes for Oxidation of Aryl Methylenes. European Journal of Organic Chemistry 2009, 2009, 503-509.

(20) Li, Y.; Lee, T. B.; Wang, T.; Gamble, A. V.; Gorden, A. E. V. Allylic C-H Activations Using $\mathrm{Cu}$ (II) 2-Quinoxalinol Salen and tert-Butyl Hydroperoxide. The Journal of Organic Chemistry 2012, 77, 4628-4633.

(21) Trammell, R.; Rajabimoghadam, K.; Garcia-Bosch, I. Copper-Promoted Functionalization of Organic Molecules: from Biologically Relevant $\mathrm{Cu} / \mathrm{O} 2$ Model Systems to Organometallic Transformations. Chemical Reviews 2019, 119, 2954-3031.

(22) Li, Y.; Lee, T.; Weerasiri, K.; Wang, T.; Buss, E. E.; McKee, M. L.; Gorden, A. E. V. 2-Quinoxalinol diamine $\mathrm{Cu}(\mathrm{ii})$ complex: facilitating catalytic oxidation through dual mechanisms. Dalton Trans. 2014, 43, 13578-13583.

(23) Tse, J. S. Ab Initio Molecular Dynamics with Density Functional Theory. Annual Review of Physical Chemistry 2002, 53, 249-290.

(24) Car, R. Introduction to Density-Functional Theory and ab-Initio Molecular Dynamics. Quantitative Structure-Activity Relationships 2002, 21, 97-104.

(25) Iftimie, R.; Minary, P.; Tuckerman, M. E. Ab initio molecular dynamics: Concepts, recent developments, and future trends. Proceedings of the National Academy of Sciences 2005, 102, 6654-6659. 
(26) Becke, A. D. Density-functional thermochemistry. III. The role of exact exchange. The Journal of Chemical Physics 1993, 98, 5648-5652.

(27) Lee, C.; Yang, W.; Parr, R. G. Development of the Colle-Salvetti correlation-energy formula into a functional of the electron density. Phys. Rev. B 1988, 37, 785-789.

(28) Stephens, P. J.; Devlin, F. J.; Chabalowski, C. F.; Frisch, M. J. Ab Initio Calculation of Vibrational Absorption and Circular Dichroism Spectra Using Density Functional Force Fields. The Journal of Physical Chemistry 1994, 98, 11623-11627.

(29) Petersson, G. A.; Bennett, A.; Tensfeldt, T. G.; Al-Laham, M. A.; Shirley, W. A.; Mantzaris, J. A complete basis set model chemistry. I. The total energies of closed-shell atoms and hydrides of the first-row elements. The Journal of Chemical Physics 1988, $89,2193-2218$.

(30) Petersson, G. A.; Al-Laham, M. A. A complete basis set model chemistry. II. Open-shell systems and the total energies of the first-row atoms. The Journal of Chemical Physics 1991, 94, 6081-6090.

(31) Frisch, M. J. et al. Gaussian 16 Revision C.01. 2016; Gaussian Inc. Wallingford CT.

(32) Martínez, L.; Andrade, R.; Birgin, E. G.; Martínez, J. M. PACKMOL: A package for building initial configurations for molecular dynamics simulations. Journal of Computational Chemistry 2009, 30, 2157-2164.

(33) Giannozzi, P. et al. Advanced capabilities for materials modelling with QUANTUM ESPRESSO. Journal of Physics: Condensed Matter 2017, 29, 465901.

(34) Perdew, J. P.; Burke, K.; Ernzerhof, M. Generalized Gradient Approximation Made Simple. Phys. Rev. Lett. 1996, 77, 3865-3868.

(35) Perdew, J. P.; Burke, K.; Ernzerhof, M. Generalized Gradient Approximation Made Simple [Phys. Rev. Lett. 77, 3865 (1996)]. Phys. Rev. Lett. 1997, 78, 1396-1396. 
(36) Zhang, Y.; Yang, W. Comment on "Generalized Gradient Approximation Made Simple". Phys. Rev. Lett. 1998, 80, 890-890.

(37) Grimme, S.; Antony, J.; Ehrlich, S.; Krieg, H. A consistent and accurate ab initio parametrization of density functional dispersion correction (DFT-D) for the 94 elements H-Pu. The Journal of Chemical Physics 2010, 132, 154104.

(38) Vanderbilt, D. Soft self-consistent pseudopotentials in a generalized eigenvalue formalism. Phys. Rev. B 1990, 41, 7892-7895.

(39) Rappe, A. M.; Rabe, K. M.; Kaxiras, E.; Joannopoulos, J. D. Optimized Pseudopotentials. Phys. Rev. B 1990, 41, 1227-1230.

(40) Dal Corso, A. Pseudopotentials periodic table: From H to Pu. Computational Materials Science 2014, 95, 337 - 350.

(41) Verlet, L. Computer "Experiments" on Classical Fluids. I. Thermodynamical Properties of Lennard-Jones Molecules. Phys. Rev. 1967, 159, 98-103.

(42) Braun, E.; Moosavi, S. M.; Smit, B. Anomalous Effects of Velocity Rescaling Algorithms: The Flying Ice Cube Effect Revisited. Journal of Chemical Theory and Computation 2018, 14, 5262-5272.

(43) Torrie, G.; Valleau, J. Nonphysical sampling distributions in Monte Carlo free-energy estimation: Umbrella sampling. Journal of Computational Physics 1977, 23, 187 - 199.

(44) Kästner, J. Umbrella sampling. Computational Molecular Science 2011, 1, 932-942.

(45) You, W.; Tang, Z.; Chang, C.-e. A. Potential Mean Force from Umbrella Sampling Simulations: What Can We Learn and What Is Missed? Journal of Chemical Theory and Computation 2019, 15, 2433-2443.

(46) Roux, B. The calculation of the potential of mean force using computer simulations. Computer Physics Communications 1995, 91, 275 - 282. 
(47) Kumar, S.; Rosenberg, J. M.; Bouzida, D.; Swendsen, R. H.; Kollman, P. A. THE weighted histogram analysis method for free-energy calculations on biomolecules. I. The method. Journal of Computational Chemistry 1992, 13, 1011-1021.

(48) Grossfield, A. WHAM: an implementation of the weighted histogram analysis method, version 2.0.9. http://membrane.urmc.rochester.edu/content/wham/.

(49) Liao, Q. In Computational Approaches for Understanding Dynamical Systems: Protein Folding and Assembly; Strodel, B., Barz, B., Eds.; Progress in Molecular Biology and Translational Science; Academic Press, 2020; Vol. 170; pp 177 - 213. 